\title{
TRAIL (Tumor Necrosis Factor-Related Apoptosis-Inducing Ligand) mediated Apoptosis of human breast cancer cells sensitized by dietary flavonoid Kaempferol
}

\author{
Yogesh Pandey ${ }^{1}$, Syed Hassan Mehdi ${ }^{2 *}$, Md. Asad Khan ${ }^{3}$, Preeti Bhatt ${ }^{1}$, Chandra Kala Pant ${ }^{\text {* }}$ \\ ${ }^{1}$ Department of Chemistry D.S.B. Campus Kumaun University Nainital, 263002 \\ ${ }^{2}$ Department of Biosciences, Jamia Millia Islamia, New Delhi. 110025 \# \\ ${ }^{2}$ Institute of Aging, Geriatrics Division, University of Arkansas for Medical Sciences, 4301 West Markham, Little Rock, AR \\ 72205, USA \\ ${ }^{3}$ Department of Biochemistry, Faculty of Dentistry, Jamia Millia Islamia, New Delhi 110025 \\ *Corresponding Author: ckp263002@gmail.com Tel No: +919990847750
}

Available online at: www.isroset.org

Received: 05/Dec/2018, Accepted: 22/Dec/2018, Online: 31/Dec/2018

\begin{abstract}
Kaempferol is one of the most prevailing flavonoid distributed in edible plants while TRAIL(tumor necrosis factorrelated apoptosis-inducing ligand)is a promising anti-cancer agent. Resistance to TRAIL, limits its potential as a drug for cancer therapy. Cytotoxicity induced by Kaempferol and TRAIL alone and in combination was measured by MTT assay. Apoptosis was detected by DNA fragmentation assay and measured by real time PCR and western blotting techniques. The study clearly showed the dose dependent cytotoxic effect of Kaempferol in combination with TRAIL in all the breast cancer cells. The dying cells showed characteristics of apoptosis such as DNA fragmentation in combined treatment with Kaempferol and TRAIL in human breast cancer cells appreciably, compared to single treatments. Furthermore, it has also been found that treatment with Kaempferol enhances TRAIL-induced apoptosis by increasing expression of apoptosisrelated proteins including caspase-3, 8, 9 and Bax and by decreasing the expression of Bcl-2. The present work for the first time shows that the combined treatment with Kaempferol and TRAIL drastically induced apoptosis in human breast cancer cells as compared to single treatment. Thus, the data clearly demonstrates that Kaempferol sensitizes human breast cancer cells to TRAIL-mediated apoptosis, which could have potential therapeutic significance in treating breast cancer.
\end{abstract}

Keywords: Apoptosis, Kaempferol; TRAIL; Breast cancer;Cytotoxicity

\section{INTRODUCTION}

In the past few decades, medicinal plants and their biologically active derivatives has increased, in relation to the possible development of novel potential drugs for several pathologies of relevant social impact [1,2]. Recently, the possible applications of medicinal plants as an antitumor agent have been widely described [3-5]. Natural products,from the extracts of medicinal plants, are used in the treatment of several health disorders such as skin, respiratory, neuromuscular, mental, obstetrics and gynecology illness [6-8]. Epidemiologic studies in humans have shown that regular consumption of fruits and vegetables is associated with reduced risk of cancer [9]. It is believed that many fruits and vegetables contain flavonoids, which could be one of the reasons to exert potential antitumorigenic activities [10]. Flavonoids possess pharmacological and biochemical effects which are capable of modulating the activity of enzymes and affect the behaviour of many cell systems in the body [11,12]. Kaempferol is a well known flavonoid in nature, which is widely distributed in plant kingdom and heavily consumedin large amounts in our daily life. Kaempferol is known to possess cancer-preventive properties [13-15]. Studies have shown that Kaempferol sensitizes the TRAIL induced apoptosis in glioma cells [16]. TRAIL also induces apoptosis in various types of malignant tumor cells, through its interaction with the death domain-containing receptor, death receptor 5 (DR5), which is also called TRAIL-R2 [17-18]. In vitro and in vivo data indicates that TRAIL is not cytotoxic to the normal cells [19-20].

Therefore, TRAIL is one of the most promising candidates for cancer therapeutics. However, some tumor cells are resistant to TRAIL-induced apoptosis[21]. It is, therefore, important to overcome this resistance for the clinical use of TRAIL in cancer 
therapy. Based on this hypothesis and reported data, the present study is aimed to evaluate the nature of Kaempferol TRAIL induced apoptosis in breast cancer cells. We hypothesized that treatment with Kaempferol enhances TRAIL-induced apoptosis by increasing expression of apoptosis-related proteins including Caspase-3, 8, 9 and Bax whereas by decreasing the expression of Bcl-2.

\section{MATERIALS AND METHODS}

2.1 Cell Culture and Treatment: To broadly cover thein vitrophenotypes exhibited by breast cancer cells, MCF-7, T47D, and ZR-75 were selected and procured from NCCS, Pune. All cell lines were grown in Dulbecco's modified Eagle medium (DMEM) supplemented with 10\% FBS and $50 \mathrm{IU} / \mathrm{ml}$ penicillin, $50 \mu \mathrm{g} / \mathrm{ml}$ streptomycin and $2 \mathrm{mM} \mathrm{L}-$ glutamine. Cells were cultured at $37^{\circ} \mathrm{C}$ in a humidified atmosphere with $5 \% \mathrm{CO}_{2}$ in air. Further, cells were treated with Kaempferol (25-200 $\mu \mathrm{M})$ alone and in different combinations with TRAIL.

2.2 Cytotoxicity assay: The cytotoxic effect were assessed in human breast cancer cells exposed to different concentrations of Kaempferol alone and in different combinations with TRAIL for 48 hours by the MTT assay as described previously (22,23). Percent inhibition of cytotoxicity were calculated as a fraction of control verses the cytotoxicity of Kaempferol, alone and in different combinations with TRAIL and expressed as $\mathrm{IC}_{50}$

2.3 Detection of apoptotic DNA fragments: DNA fragmentation was detected by agarose gel electrophoresis. $1 \times 10^{6}$ breast cancer cells were plated in $30 \mathrm{~mm}$ culture plate. When the cells reached approximately $70 \%$ confluency, Kaempferol was added alone and in different combinations with TRAIL and the cells were incubated for 48 h. After 48 hours, cells were harvested and pelleted by centrifugation (Eppendorf 5804R, Germany). Cellular DNA was extracted by SDS/proteinase $\mathrm{K}$ treatment, phenolchloroform extraction, and ethanol precipitation as described previously[22] and then dissolved and stored in TE buffer and the DNA samples obtained were analyzed by $2 \%$ agarose gel electrophoresis. After electrophoresis, the gels were stained with ethidium bromide, and visualized as a DNA ladder with UV.

\subsection{Apoptosis measurements}

2.4.1 Quantitative real-time PCR: Harvested cells were lysed in RLT buffer and total RNA was extracted using RNeasy Plus Mini Kit (Qiagen, USA). RNA was quantified and $1 \mu \mathrm{g}$ RNA was used for cDNA synthesis using High-Capacity cDNA Reverse Transcription Kit (Applied Biosystems, $\quad$ USA). 20 ngof synthesized cDNA were used for quantitative real time according to the manufacturer's protocol using $2 \mathrm{x}$ SYBR Green qPCR Master Mix (Biotool, USA) on BioRad CFX 96 well machine.
2.4.2 Western Blotting: Harvested cells were lysed and cleared by centrifugation at $13,000 \mathrm{rpm}$ for $20 \mathrm{~min}$ at $4^{\circ} \mathrm{C}$. The supernatant was stored at $-70^{\circ} \mathrm{C}$ until use. The protein concentration was quantified by BCA Assay method. Next, total proteins $(15-20 \mu \mathrm{g})$ were electrophoresed using $12 \%$ reducing SDS-polyacrylamide gels and transferred to nitrocellulose membranes. After blocking with $0.1 \%$ Tween20 in PBS (PBST) containing 1\% skim milk and 1\% BSA for $1 \mathrm{~h}$, the membranes were incubated overnight at $4{ }^{\circ} \mathrm{C}$ with the indicated primary antibodies. After washing in $1 \mathrm{X}$ PBST for $15 \mathrm{~min}$ ( 3 times $\mathrm{x} 5 \mathrm{~min}$ ), the membranes were incubated with diluted enzyme-linked secondary antibodies. After washing in $1 \mathrm{X}$ PBST for $1 \mathrm{~h}$ (4 times $\mathrm{x} 15 \mathrm{~min}$ ), the protein bands were detected using the EZ-western chemiluminescent detection kit and visualized by exposing the membranes to X-ray films. All protein bands were normalized against $\beta$-actin protein.

\section{RESULTS}

\subsection{Kaempferol sensitizes MCF-7, T47D and ZR-75 cells for TRAIL induced cytotoxicity}

Effect of Kaempferol on breast cancer cells were shown in Figure 1. Kaempferol alone is not inducing cytotoxicity in all the breast cancer cells even at higher concentration i.e., $200 \mu \mathrm{M}$. Figure 2 showed that Kaempferol $(200 \mu \mu \mathrm{M})$ alone did not inhibit cell viability in all the breast cancer cells in a dose-dependent manner within 24h. Similarly, TRAIL (25-200 ng/mL) did not have a significant effect on cell viability. Kaempferol enhanced the inhibitory effects of TRAIL on cell viability in all the breast cancer cells within $24 \mathrm{~h}$ (Figure 2). Compared with control cells, addition of Kaempferol in combination with TRAIL decreased viability by more than $50 \%$ in all the breast cancer cells.

\subsection{Validation of apoptosis measurement by DNA laddering}

In the given results, the cells were treated with Kaempferolalone and in different combinations with TRAIL, and the DNA was directly extracted and run on agarose gel. DNA hyperfragmentation, if presented, was seen as a stepwise ladder of DNA fragments. Figure 3 shows that DNA laddering is pronounced in the samples where cells were treated with Kaempferol and TRAIL together in all the breast cancer cell lines. These results confirm that Kaempferol promotes TRAIL induced apoptosis in breast cancer cells.

\subsection{Kaempferol Augments TRAIL-Induced Apoptosis through Caspase Activation}

Quantitative real time PCR wasperformedto analyze the extrinsic and intrinsic apoptotic pathways in TRAIL-induced and TRAIL-Kaempferol - induced apoptosis. By analyzing caspase-3,8 and 9 it has been found that all the three caspases are upregulated in TRAIL-Kaempferol- 
induced apoptosis in all the three breast cancer cells (Figure 4).

\subsection{Regulation of Bcl-2 Family Members by Kaempferol} Bcl-2 family members regulate apoptosis induced by stress stimuli primarily at the level of mitochondria [23].Therefore, the effects of Kaempferol in combination with TRAIL on the expression of Bcl-2 family proteins have been examined here. Real time PCR and western blot analysis showed that on treatment with Kaempferol in combination with TRAIL, the expression of the anti-apoptotic proteins $\mathrm{Bcl}-2$ was decreased significantly in all the three breast cancer cells whereas Bax expression is increased (Figure 5). Furthermore, we also performed western blot analysis to confirm our findings at protein level. Treatment of Kaempferol significantly increases the expression of caspase-3, caspase-9, caspase-8 and Bax whereas Bcl-2 expression is decreased in TRAIL induced apoptosis in all the three breast cancer cells (Figure 6).

Results suggested that the combination of Kaempferol and TRAIL could be an effective approach for breast cancer therapy and sensitization of TRAIL-induced cytotoxicity in cancer cells by a combination of TRAIL and Kaempferol may be particularly relevant in retaining the cancer-killing activity and circumventing the cancer-promoting potential of TRAIL. In vivo experiments with animal models are needed to verify the efficacy of the TRAIL and Kaempferol combination for breast cancer therapy.

\section{DISCUSSION}

We have been made to enhance the survival of breast cancer patients by targeting resistance to apoptosis. TRAIL induces apoptosis in cancer cells with almost minimal toxicity[24].However, breast cancer cells develop resistant to TRAIL therapy [25]. Therefore, in the present investigation it has been aimed to sensitize the TRAIL induced apoptosis in breast cancer cells byusing Kaempferol, an essentialflavonoid. Kaempferol is known to have anticancer efficacy against a broad range of cancers in cell culture studies. Our findings suggests that Kaempferol may be useful as an anticancer drug or as an adjunct in combination therapy to enhance TRAIL induced apoptosis in breast cancer cells. Cellular proliferation depends on the rates of cell division and death and thus, many anticancer drugs have been used to prevent cancer cell division in order to inhibit cancer cell proliferation. In vitro cytotoxicity assays can be used to predict human toxicity and for the general screening of chemicals [26,27]. In this study, it has been shown for the first time that Kaempferol in combination with TRAIL reduced the viability of breast cancer cell in culture. However, separate administration of Kaempferol and TRAIL did not show significant reduction in cell growth in all the three breast cancer cells. Combined application of TRAIL and Kaempferol strongly reduced the cell viability upto $\sim 80 \%$. Apoptosis is a physiological process of cell death. DNA fragmentation is one of the hallmarks of cell apoptosis. The results revealed that the apoptosis proportion of cells was increased by the administration of Kaempferol and TRAIL in combination in all the breast cancer cells. Studies also have shown that Kaempferol modulates expression of genes involved in apoptosis $\quad[14,15]$. The present findings detected the suppression of Bcl-2 and significantly increased expression of caspase- 3 caspase- 9 and caspase- 8 and Bax in all the three breast cancer cells.

\section{CONCLUSION}

Previous findings have not shown many reports on TRAIL mediated apoptosis of human breast cancer cells sensitized by dietary flavonoid Kaempferol till date. In the present study, kaempferol sensitizes the TRAIN induced apoptosis in breast cancer cells. However, the future studies are needed to confirm role of kaempferol in TRAIN mediated apoptosis in breast cancer cells as well as other cancer types.

\section{CONFLICT OF INTEREST}

None

\section{ACKNOWLEDGEMENT}

The authors would like to acknowledge the Department of Chemistry for providing the research facility.

\section{REFERENCES}

[1]. I.Hedberg, "Botanical methods in ethnopharmacology and the need for conservation of medicinal plants" Journal of Ethnopharmacology, Vol.38, pp.121-28,1993.

[2]. M. Heinrich, S. Gibbons "Ethnopharmacology in drug discovery: an analysis of its role and potential contribution" Journal of Pharmacy and Pharmacology, Vol.53, pp. 425-32, 2001

[3]. N. Katsube, K.Iwashita, T. Tsushida, K. Yamaki, M. Kobori, "Induction of apoptosis in cancer cells by Bilberry (Vacciniummyrtillus) and the anthocyanins" Journal of Agricultural and Food Chemistry, Vol.51, pp. 68-75, 2003.

[4]. MA. Richardson, "Biopharmacologic and herbal therapies for cancer: research update from NCCAM" Journal of Nutrition, Vol. 131, pp. 3037-40, 2001

[5]. M.J. Wargovich, C. Woods, D.D.Hollis, M.E.Zander , "Herbals, cancer prevention and health" Journal of Nutrition Vol. 131, pp. 3034-36, 2001.

[6]. K.A.Abo, A.A. Adeyemi, D.A. Adeite, "Ethnobotanical survey of plants used in the treatment of infertility and sexually transmitted diseases in southwest Nigeria" African Journal of Medical Sciences, Vol. 29, pp.325-27, 2000

[7]. A. Ankli et al, "Yucatec Mayan medicinal plants: evaluation based on indigenous uses" Journal of Ethnopharmacology Vol. 79, pp. 43-52. 2002 
[8]. G. Pinn, "Herbs used in obstetrics and gynaecology" Australian Family Physician Vol. 30,pp. 351-56, 2001

[9]. Y.J. Surh, "Cancer chemoprevention with dietary phytochemicals" Nature Review Cancer Vol.3,pp.768-80, 2003

[10]. C.S.Yang et al, "Inhibition of carcinogenesis by dietary polyphenolic compounds" Annual Review of Nutrition, Vol.21,pp. 381-06, 2001

[11]. K. Bimlesh el a., "A Review of Phytochemistry and Pharmacology of Flavonoids" International Journal of Pharmaceutical Sciences, Vol.1,pp. 25-41, 2011

[12]. D. Agarwal, "Pharmacological Activities of flavonoids" International Journal of Pharmaceutical Sciences and Nanotechnology, Vol. 4, pp. 1394-98, 2011.

[13]. H.W. Leung el a., "Kaempferol induces apoptosis in human lung non-small carcinoma cells accompanied by an induction of antioxidant enzymes" Food and Chemical Toxicology,Vol. 45,pp. 13, 2007.

[14]. V. Sharma el al, "Kaempferol induces apoptosis in glioblastoma cells through oxidative stress" Molecular Cancer Therapeutics, Vol.6, pp.2544-53, 2007.

[15]. T.T.Nguyen et al, "Kaempferol-induced growth inhibition and apoptosis in A549 lung cancer cells is mediated by activation of MEK-MAPK" Journal of Cellular Physiology, Vol. 197, pp. $110-121,2003$.

[16]. Q. Zhou et al, "Luteolin inhibits invasion of prostate cancer PC3 cells through E-cadherin" Molecular Cancer Therapeutics, Vol.8, pp. 1684-91, 2009

[17]. J.P. Sheridan et al, "Control of TRAIL-induced apoptosis by a family of signaling and decoy receptors" Science, Vol. 277, pp.818-21, 1997.

[18]. H.Walczak et al, "TRAIL-R2: a novel apoptosis-mediating receptor for TRAIL" EMBO Journal, Vol.16, pp. 5386-97, 1997.

[19]. H. Walczak et al, "Tumoricidal activity of tumor necrosis factor-related apoptosis-inducing ligand in viv" Nature Medicine, Vol. 5, pp.157-63, 1999.
[20]. D. Lawrence et al, "Differential hepatocyte toxicity of recombinant Apo2L/TRAIL versions" Nature Medicine, Vol.7, pp. 383-85, 2001.

[21]. L. Zhang, B. Fang, "Mechanisms of resistance to TRAILinduced apoptosis in cancer" Cancer Gene Therapy, Vol.12, pp. 228-37, 2005.

[22]. S.H. Mehdi, A. Qamar, "Paraquat-induced ultrastructural changes and DNA damage in the nervous system is mediated via oxidative-stress induced cytotoxicity in Drosophila melanogaster" Toxicological Sciences, Vol.134 (2), pp. 355365, 2013.

[23]. S.H. Mehdi, A. Qamar, Md. Zafaryab, S. Nafees, M.A. Rizvi, “ Malathion induced cell injury and cell death in the nervous system via oxidative stress induced cytotoxicity in Drosophila melanogaster" International Journal of Scientific Research, Vol. 6 (12), pp. 447-450, 2018.

[24]. J. Sambrook, D.W. Russell, "Molecular Cloning: A Laboratory Manual" Cold Spring Harbor Laboratory Press, Vol. $3^{\text {rd }}, 2001$.

[25]. M.K. Manion, D.M. Hockenbery, "Targeting BCL-2-related proteins in cancer therapy" Cancer Biology and Therapeutics, Vol. 2, pp.105-14, 2003.

[26]. H.N. LeBlanc, A. Ashkenazi, "Apo2L/TRAIL and its death and decoy receptors" Cell Death and Differentiation, Vol. 10, pp.66-75, 2003.

[27]. Y. Zhang, B. Zhang, "TRAIL resistance of breast cancer cells is associated with constitutive endocytosis of death receptors 4 and 5" Molecular Cancer Research. Vol. 6(12), pp.1861-71, 2008.

[28]. C. Clemedson, B. Ekwall,"Overview of the final MEIC results: The in vitro-in vitro evaluation" Toxicology In Vitro, Vol. 13, pp.657-63, 1999.

[29]. M.E. Scheers, B.A. Ekwall, J.P. Dierickx, "In vitro long-term cytotoxicity testing of 27 MEIC chemicals on HepG2 cells and comparison with acute human toxicity data" Toxicology In Vitro Vol.15, pp. 153-61, 2001

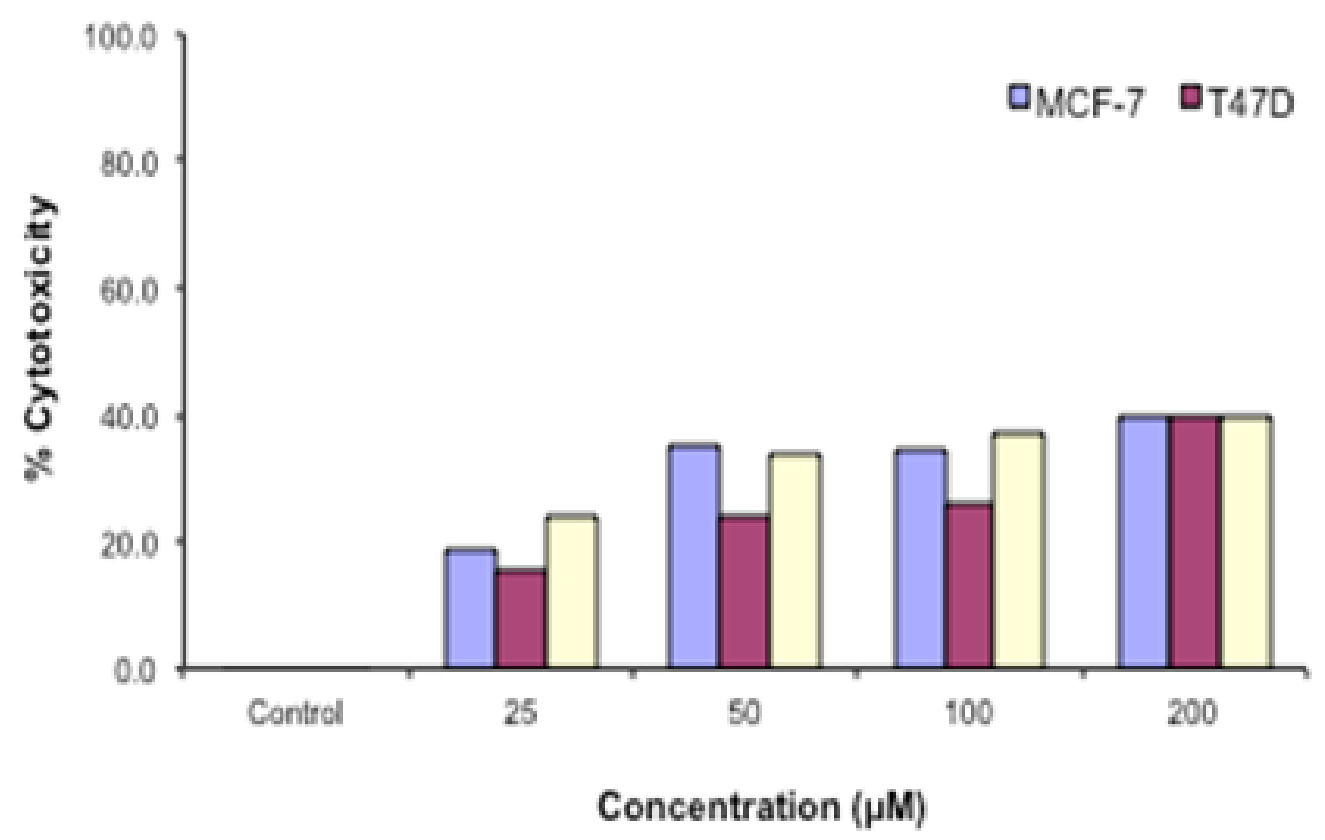


Figure I: Kaempferol effect on breast cancer cells

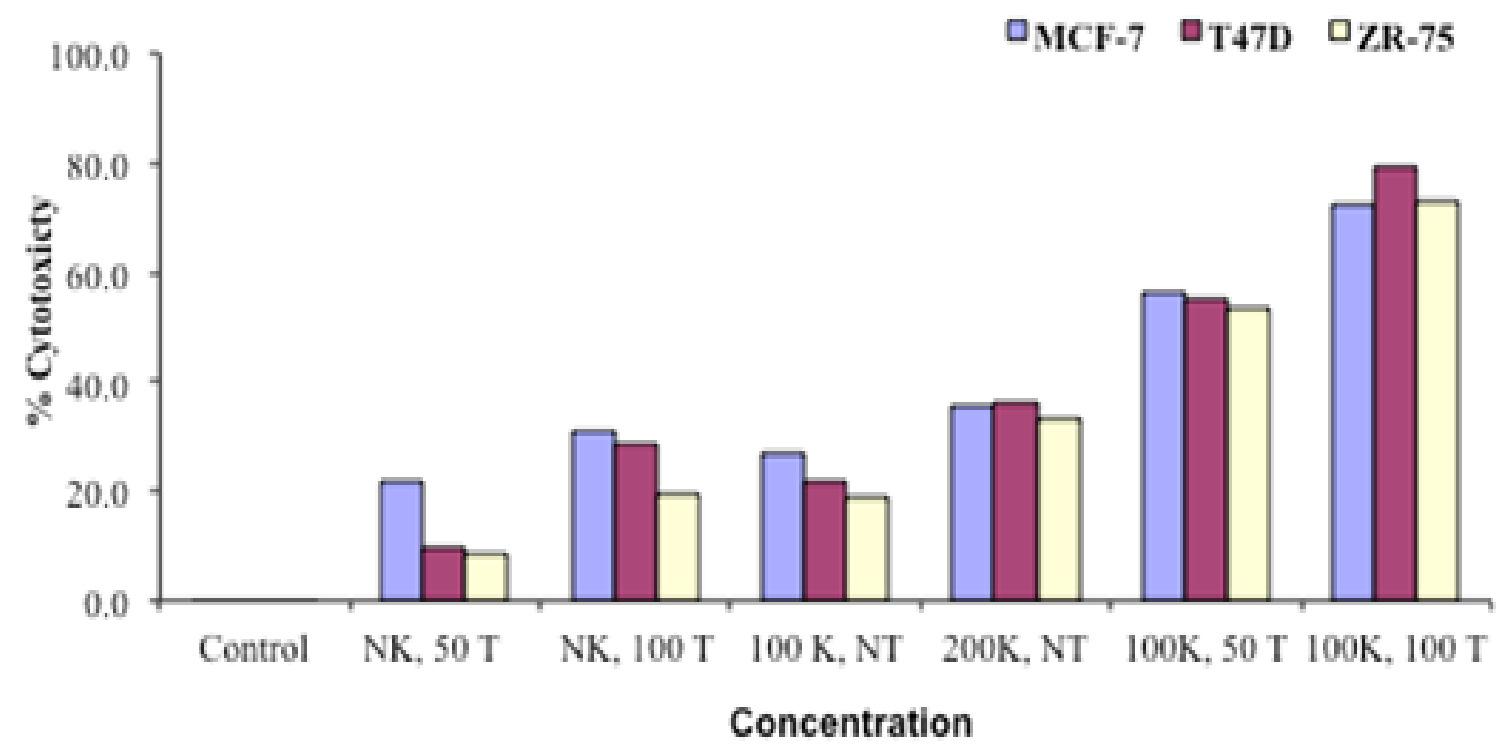

Figure II: Kaempferol sensitized TRAIL induced cytotoxicity in breast cancer cells. (NOTE: NK: No Kaempferol, 50T:

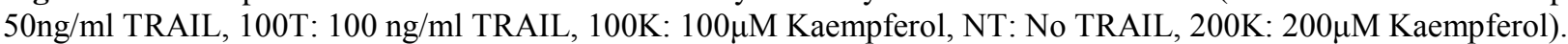

MCF-7

T47D

ZR-75

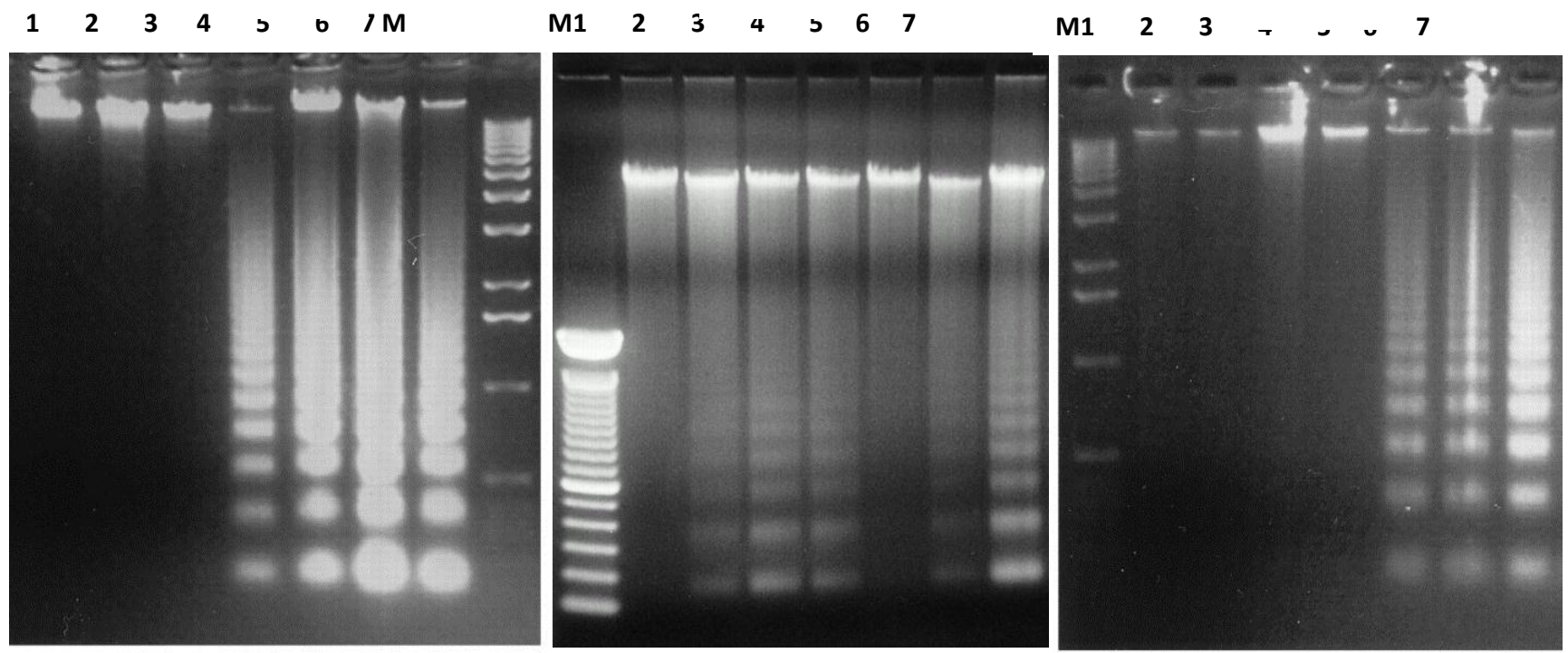

Figure III: DNA fragmentation analysis in TRAIL-kaempferol - induced apoptosis in human breast cancer cells.(Note: $\mathrm{M}=$ Marker; $1=$ Control; $2=\mathrm{NK}, 50 \mathrm{~T} ; 3=\mathrm{NK}, 100 \mathrm{~T} ; 4=100 \mathrm{~K}, \mathrm{NT} ; 5=200 \mathrm{~K}, \mathrm{NT} ; 6=100 \mathrm{~K}, 50 \mathrm{~T} ; 7=100 \mathrm{~K}, 100 \mathrm{~T}$ ). 
A

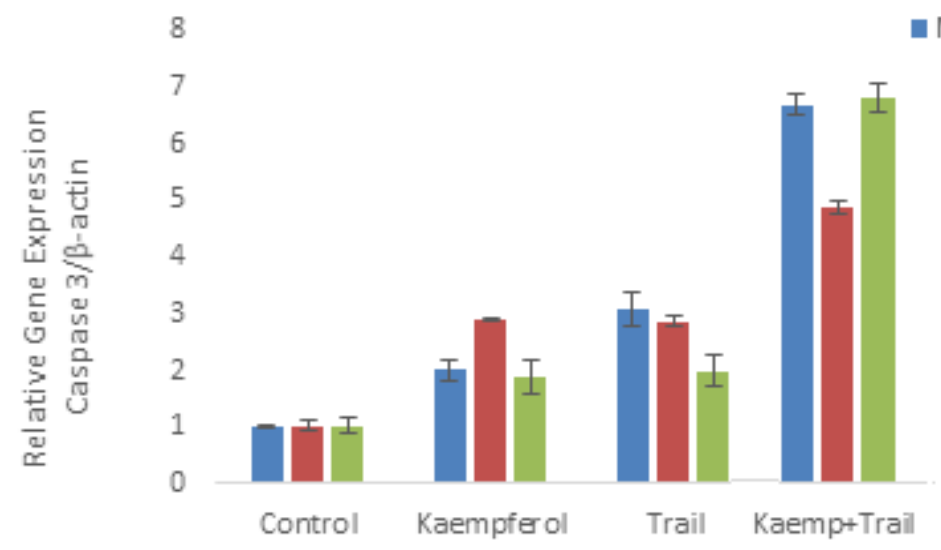

B

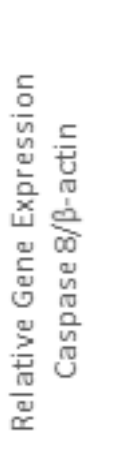

6
MCF $\square$ T47D ZZR-75

a MCF $\quad$ T47D $\quad$ ZR-75

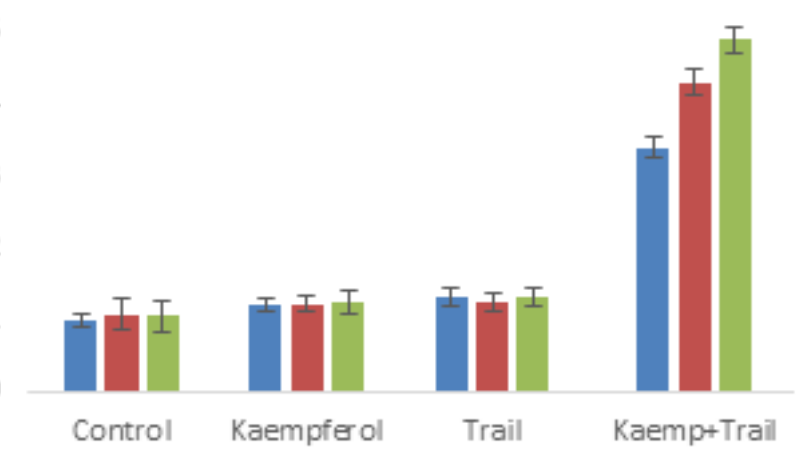

C $\square$ MCF-7 $\quad$ T47D $\quad$ ZR-75

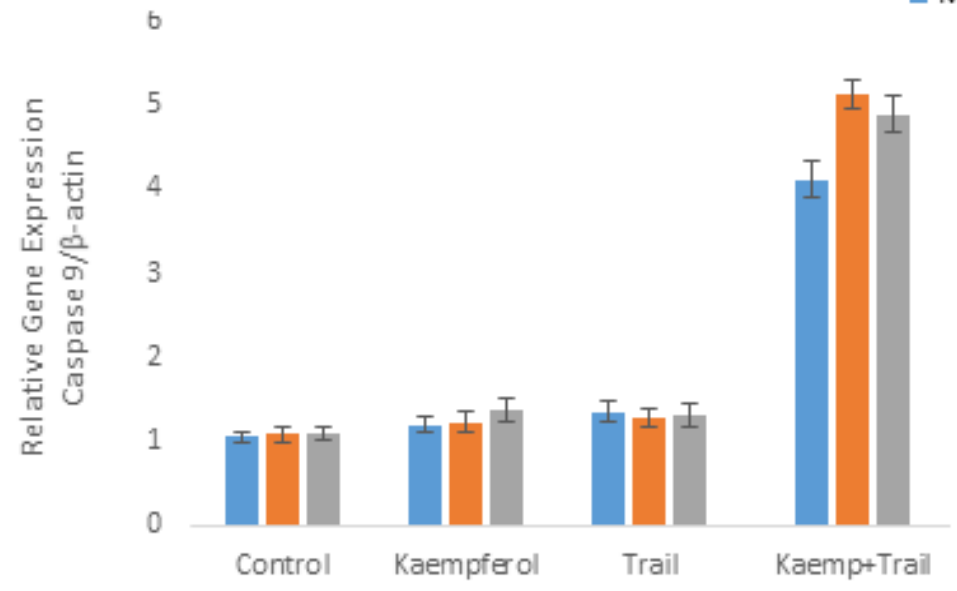

Figure IV: Quantitative Real Time PCR showing the effect of kaempferol on TRAIL induced caspase-3, caspase-9, caspase-8 expression in human breast cancer cells. 


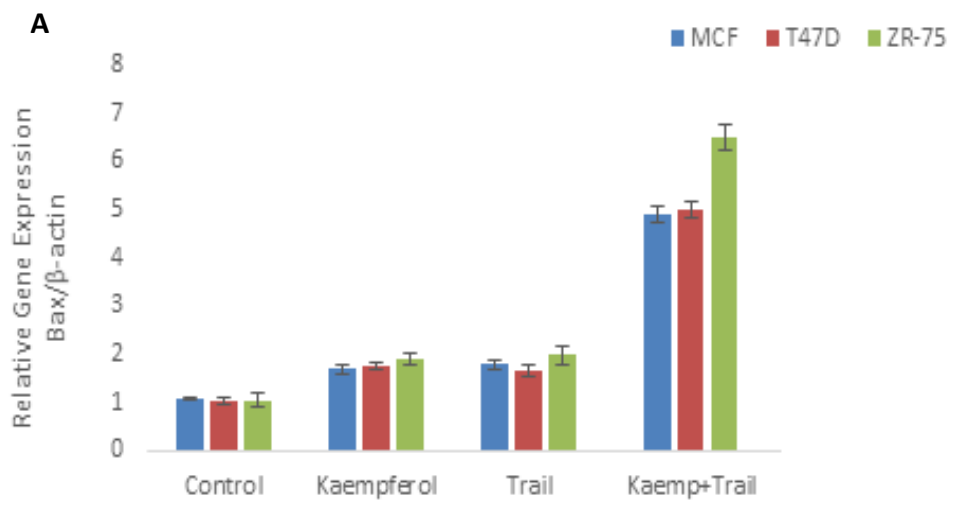

B

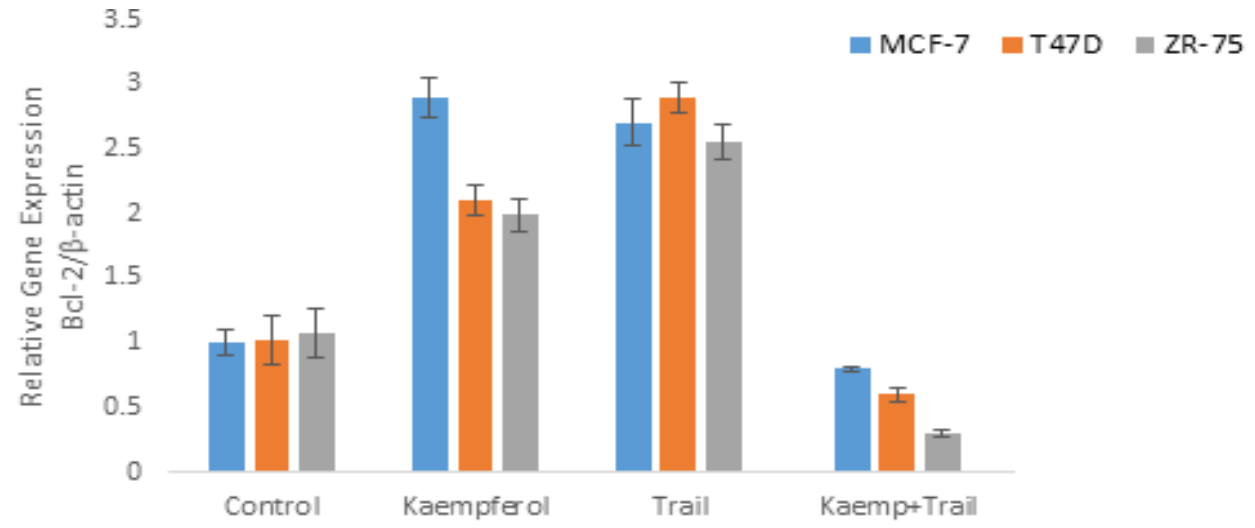

Figure V: Quantitative Real Time PCR showing the effect of kaempferol on TRAIL induced Bcl-2 and Bax expression in human breast cancer cells.

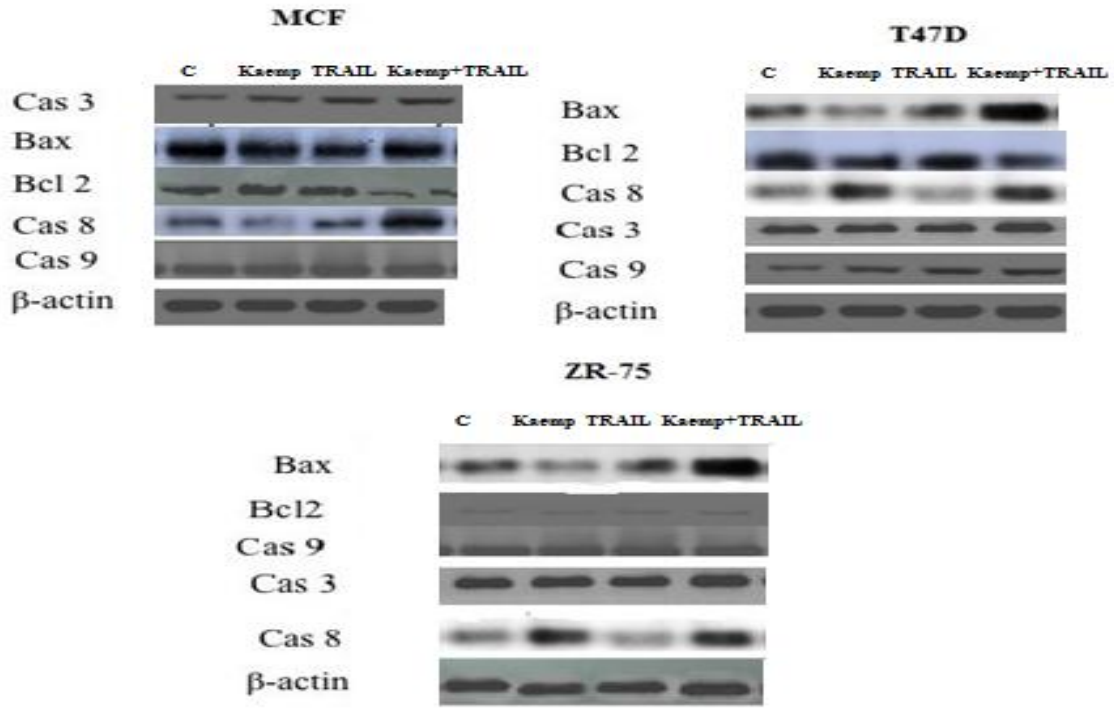

Figure VI: Immunoblotting showing the effect of kaempferol on TRAIL induced caspase-3, caspase-9, caspase-8, Bax and Bcl-2 expression in human breast cancer cells. 